\title{
Study on Model of Bathtub Water Temperature in Time and Space
}

\author{
Bo Chen
}

School of North China Electric Power University, Baoding 071003, China.

735303777@qq.com

Keywords: Model of water temperature finite difference method Gauss-Seidel iteration

\begin{abstract}
This paper is intended to study the model of bathtub water temperature in time and space. First of all, a differential function model is chosen as the basic model. Based on the differential function model, the new model considers factors of dissipating heat from water surface and the bathtub. Under the condition without human motions, this paper gets the model of tub water temperature in time. Then, the article solves the modified model including human motions using four-order Runge-Kutta Algorithm to make sure the accuracy of the differential function. Next, the paper obtains the complete model of tub water temperature in time. According to heat transfer theory and finite difference method, this paper develops a planar model of tub water temperature in space, and uses Gauss-Seidel iteration method to compute the solution of the model. Then, an isothermal figure is got. At last, this paper concludes that water temperature distributes almost evenly throughout the bathtub by utilizing model of bathtub water temperature in space.
\end{abstract}

\section{Introduction}

Runbo Wei made great achievements on heat transfer between human body and the environment ${ }^{[1]}$. GunnebergF researched the heat transfer rate of water surface and impacts of air speed on dissipating heat coming from the water surface ${ }^{[2]}$. There are a lot of factors that have effects on temperature of bathtub water. For the purpose of modeling to find out the relationship between bathtub water temperature and time or space reasonably and clearly, we adopt an analytical method analogous to Single Variable, which is, considering single factor or some in sequence. We ignore the factor of adding water while modeling.

\section{Model One: Model of Water Temperature in Time}

\subsection{Model Building}

Before we build the model, it's necessary to give some assumptions: 1) Assume that the bathtub is full of water with the person lying inside. 2) Assume that no water is injected into the bathtub in the model.

\subsubsection{Heat Elimination of water surface and wall of bathtub}

At first, we only consider heat elimination of water surface and the wall of bathtub. The user of bathtub is not included into the condition above, that is to say, heat exchange between human body and circumstances is not considered temporarily. At the moment, heat elimination can be described by the following equation.

$$
\begin{aligned}
& \Phi=A q=\lambda A \cdot \frac{t_{s}-t_{a}}{\delta} \\
& \Psi=\phi_{L}=\left(\phi_{b r}+\phi_{e}+\phi_{c}\right) \\
& =\left(\left(\varepsilon \sigma T_{s}^{4}+f\left(u_{z}\right) \cdot L\left(T_{s}\right)\left(e_{s}-e_{a}\right)+\frac{C_{p} \cdot p}{0.62}\left(T_{s}-T_{a}\right)\right)\right.
\end{aligned}
$$

Where:

$\Phi$ is the heat dissipating capacity of the wall of bathtub.

$\Psi$ is the heat dissipating capacity of the water surface.

Ts is degree Celsius of bathtub water, while ta is degree Celsius of air above the water surface. 
$\Phi_{b r}$ is heat flux of inverse radiation of water surface.

$\Phi_{e}$ is evaporative heat dissipating capacity of water surface.

$\Phi_{c}$ is the quantity of conductive heat dissipation.

2.1.2 Heat exchange between human body and circumstances

Taking the person into consideration, we only consider temporarily the condition without motions made by human. Under the circumstances, we analyze the heat exchange between human body and the environment.

\section{Step 1: calculation of surface area of human body}

The surface area of human body can be described by the following equation:

$$
A p=0.61 H_{\text {man }}+0.0128 W_{\text {man }}-0.1529
$$

Where:

$A_{p}$ is the surface area of human body,

$H_{\text {man }}$ is his height,

$W_{\text {man }}$ is his weight.

Step 2: determining the change of the temperature of body surface with respect to time

The change of the temperature of body surface with respect to time is described by the following equation:

$$
T_{c l}=a+b \ln (\tau+k)
$$

Where:

$T_{c l}$ is the temperature of body surface. Parameter $\mathrm{a}, \mathrm{b}$ and $\mathrm{k}$ are constants. When the temperature reaches a certain value, due to the body's own regulation, body surface temperature remains unchanged. We assume it is 37 degrees Celsius.

Table 1: data used to computing parameter $\mathrm{a}, \mathrm{b}$ and $\mathrm{k}$

\begin{tabular}{cc}
\hline$T_{c l}$ in unit of degree Celsius & in unit of minute \\
\hline 33.8 & 0 \\
35 & 1 \\
35.8 & 2 \\
\hline
\end{tabular}

By substituting values in Table 1 to equation (2.4), we then figure out values of a, $\mathrm{b}$ and $\mathrm{k}$ equal 32.84, 2.36, 1.50, respectively.

\section{Step 3: heat exchange between human body and environment}

We devise the set of following equations:

$$
\begin{aligned}
& Q=M-W-R-C \\
& W=K \times M \\
& R=\frac{A_{e}}{A} \eta \sigma\left((a+b \ln (\tau+k))^{4}-T_{m r}{ }^{4}\right) \\
& C=h_{c}\left((a+b \ln (\tau+k))-t_{m r}\right) \\
& h_{c}=B V^{n}=5.1
\end{aligned}
$$

Where:

$Q$ is the variation of human body heat.

$\mathrm{M}$ is the average metabolic rate of 20 -30-year-old man. $\mathrm{M} \approx 94 \mathrm{~W} / \mathrm{m} 2$

$\mathrm{W}$ is the work that human applies to the outside.

$\mathrm{R}$ is quantity of radiant heat exchange between human body and environment.

$\mathrm{C}$ is quantity of convective heat exchange between human body and environment.

$\mathrm{Tcl}$ is temperature of human body surface.

Tmr is temperature of the environment.

2.1.3 Change of bathtub water temperature with respect to time

According to equations above, we successfully determine the function of change of the temperature with respect to time t. 


\section{Step 1: without motions created by human}

$$
\begin{aligned}
& \Psi d \tau+\Phi d \tau+(R+C) A_{p} d \tau=-c m d t_{S} \\
& R=\eta \sigma\left((a+b \ln (\tau+k))^{4}-T_{m r}{ }^{4}\right) \\
& C=h_{c}\left((a+b \ln (\tau+k))-t_{m r}\right)
\end{aligned}
$$

The left part of equation (2.10) represents heat exchange between bath water and environment; while that in the right represents variation of bath water heat per unit time. We set that sigh of dissipating heat is positive while the absorptive is negative.

\section{Step 2: with motions created by human}

We successfully devise the function that describes the relationship between water temperatures with time in the last step. We, then, take motions into consideration. We believe that it is necessary to figure out the impact of human actions on the environment. At last, we set the optimal function.

Here are some assumptions:

- Assume that the person applies work to water by motions.

- Assume that human motion increases water velocity.

- Assume that other effects caused by human motion are without consideration.

Here is the optimal function:

$\Psi d \tau+\Phi d \tau+(R+C+W) A_{p} d \tau=-c m d t_{S}$

\subsection{Model Results}

To solve the differential equation (2.13) in the last section, and then demonstrate better the change in bathing water temperature with time during bathing, we plot over a whole range of time in Figure 1.

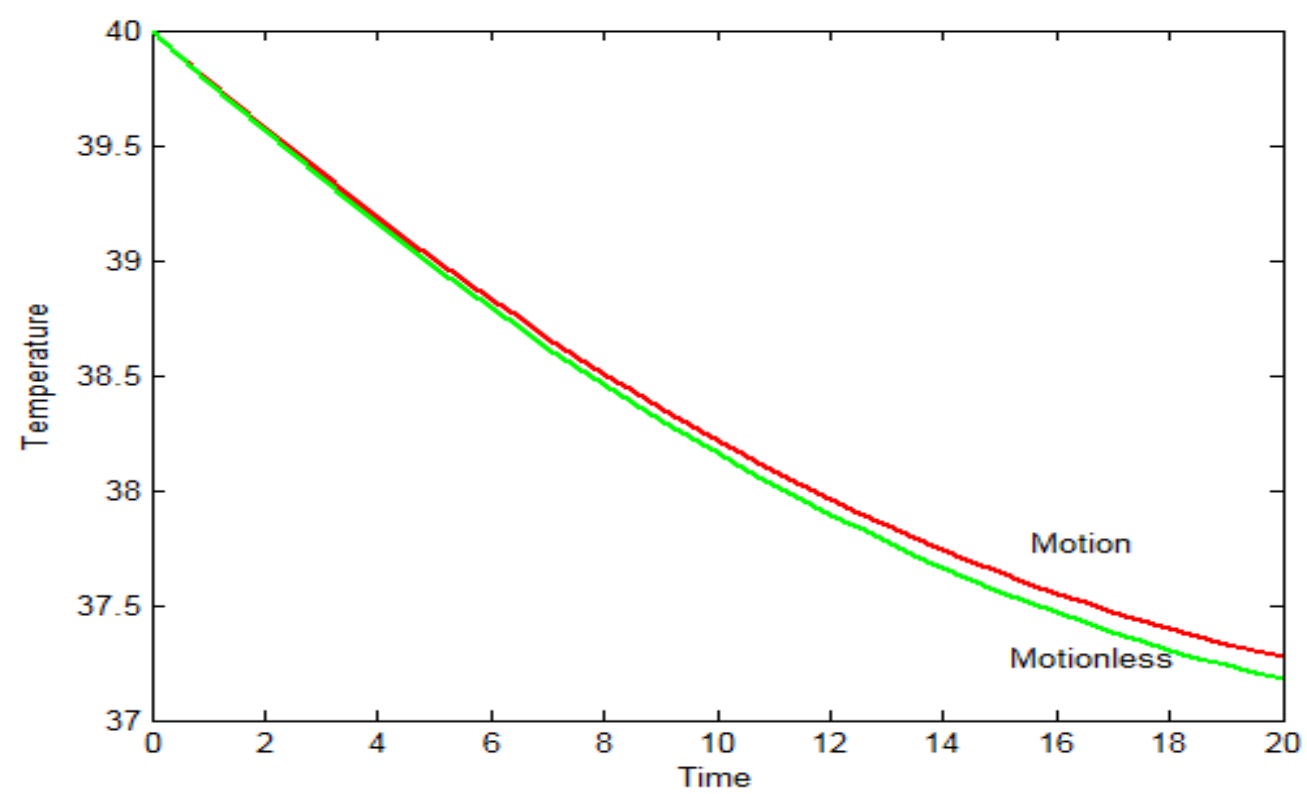

Figure 1: curves of bathtub water temperature change with time

The results of final temperature are presented in Table 2.

Table 2: eventual temperature of water

\begin{tabular}{ccc}
\hline condition & motion & motionless \\
\hline value $/{ }^{\circ} \mathrm{C}$ & 37.18 & 37.27 \\
\hline
\end{tabular}

By analyzing the above results, we can find that bathtub water temperature decreases as time increases, down to $37.18^{\circ} \mathrm{C}$ with motions while $37.27^{\circ} \mathrm{C}$ motionless. Additionally, we can come to a conclusion that human action accelerates to minify the water temperature, but the effect is not very large.

\subsection{Model Testing}

According to values of parameters coming from a producer of bathtubs, we learn that the temperature of bathtub water decreases about $5^{\circ} \mathrm{C}$ per hour; $3^{\circ} \mathrm{C}$ per half an hour. Through the 
simulation in MATLAB, we find that the temperature decreases $3^{\circ} \mathrm{C}$ without motions per half an hour; $4.7^{\circ} \mathrm{C}$ per hour. By comparison, we deem that this model is rather credible.

\section{Model Two: Model of Water Temperature in Space}

In this model, we apply finite difference method and Gauss-Seidel iteration method to establish a thermal physical model. We expect to indicate the distribution of water temperature by this model. And then we do the simulation in MATLAB to compute numerical solutions.

\section{Step One: Do the region discretization}

$\checkmark$ Let X-axis represents width of the bathtub which equals a in total. There are M nodes in $\mathrm{X}$-axis, where the step length $\Delta x=\mathrm{a} /(M-1)$

$\checkmark \quad$ Let $\mathrm{Y}$-axis represents length of the bathtub which equals $\mathrm{b}$ in total. There are $\mathrm{N}$ nodes in $\mathrm{Y}$-axis, where the step length $\Delta y=\mathrm{b} /(N-1)$

\section{Step Two: Establish discretization function}

For inner nodes:

$$
\lambda \Delta y \frac{t_{m-1, n}-t_{m, n}}{\Delta x}+\lambda \Delta y \frac{t_{m+1, n}-t_{m, n}}{\Delta x}+\lambda \Delta x \frac{t_{m, n+1}-t_{m, n}}{\Delta y}+\lambda \Delta x \frac{t_{m, n-1}-t_{m, n}}{\Delta y}=0
$$

For nodes in surface of hot water:

$\lambda \frac{\Delta y}{2} \frac{t_{m-1,1}-t_{m, 1}}{\Delta x}+\lambda \frac{\Delta y}{2} \frac{t_{m+1,1}-t_{m, 1}}{\Delta x}+h \Delta y\left(t_{\infty}-t_{m, 1}\right)+\lambda \Delta x \frac{t_{m, 2}-t_{m, 1}}{\Delta y}=0$

\section{Step Three: Results}

After clearing up functions above, we use Gauss-Seidel iteration method under the condition that absolute error $<0.001$.

Here is the simulation result as shown below:

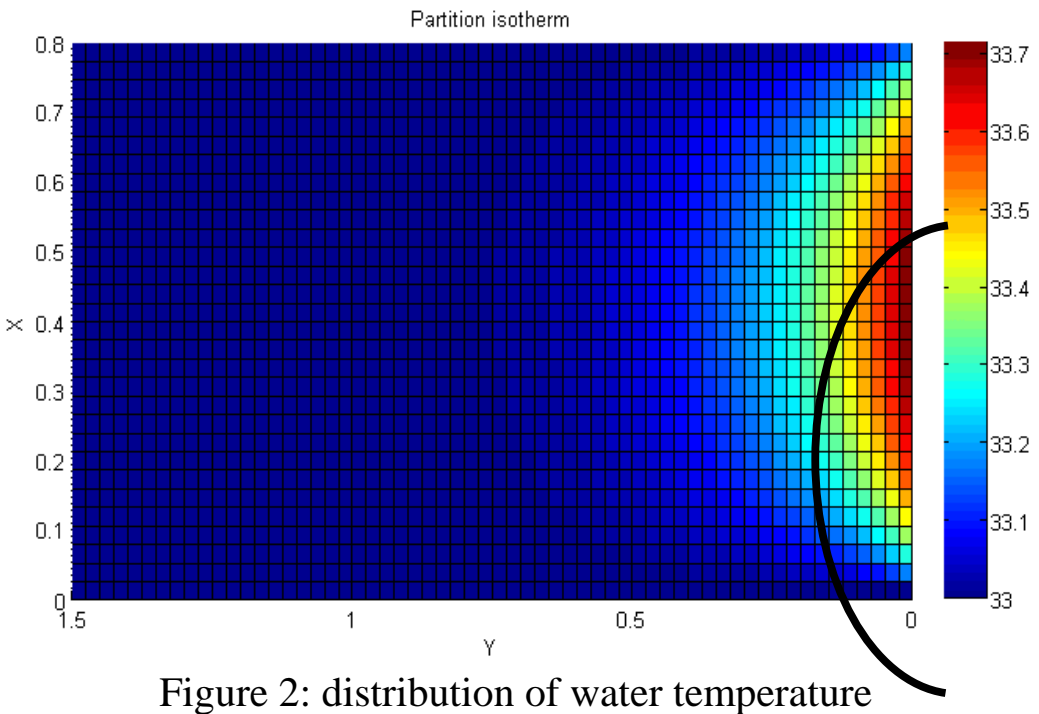

From the figure, we can see that the percentage of the region where temperature is over $40{ }^{\circ} \mathrm{C}$ (namely, the region inside the black line) is only 5.56\%. Accordingly, we deem that temperature distributes evenly throughout the bathtub.

\section{References}

[1] Wei Runbo, Human calculation method of heat exchange with the environment, Ergonomics 2 (1995): 39-42.

[2] Zhang Shunong, Tong Liang, Laboratory experimental study on heat transfer coefficient of the water, Water Protection 2 (1986).

[3] Li Jianpu, Fast computation of temperature field. Shanghai Normal University, 2010. 